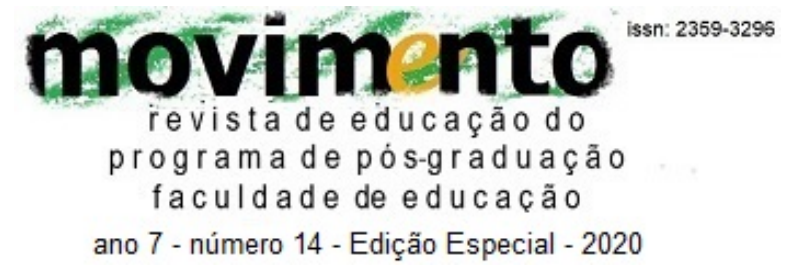

\title{
MEIO SÉCULO DE PÓS-GRADUAÇÃO NO BRASIL: DO PERÍODO HERÓICO AO PRODUTIVISMO PELA MEDIAÇÃO DE UM MODELO SUPERIOR ÀS SUAS MATRIZES
}

\author{
Dermeval Saviani \\ Universidade Estadual de Campinas (UNICAMP) \\ Campinas, SP, Brasil \\ DOI: https://doi.org/10.22409/mov.v7i14.46475
}

\begin{abstract}
RESUMO
Partindo da caracterização da instituição universitária e de sua manifestação no Brasil, este artigo considera, num primeiro momento, os antecedentes da pósgraduação no Brasil para examinar, em seguida, a estrutura do Parecer $n^{\circ}$ 977/65 que tratou da conceituação da pós-graduação dando início ao processo de sua institucionalização que teve sequência com sua regulamentação normatizada pelo Parecer $n^{\circ} 77 / 69$. No terceiro momento analisa o processo de implantação da pós-graduação no Brasil que se configurou como um novo modelo superior aos dois modelos dos quais se originou: o norteamericano e o europeu. Na sequência levanta o problema dos riscos de descaracterização do modelo brasileiro de pós-graduação representados pelo produtivismo, o que conduz ao exame do dilema produtividade-qualidade na pósgraduação, concluindo com a apresentação de estratégias para evitar a descaracterização da bem sucedida experiência brasileira de pós-graduação.
\end{abstract}

Palavras-chave: Educação Brasileira. Universidade. Pós-Graduação.

\section{HALF CENTURY OF GRADUATE STUDIES IN BRAZIL: FROM THE HEROIC PERIOD TO PRODUCTIVISM BY MEDIATING A MODEL SUPERIOR TO ITS MATRIXS}

\begin{abstract}
ABSCRACT
Starting from the characterization of the university institution and its manifestation in Brazil, this article considers, at first, the antecedents of graduate studies in Brazil, and then examines the structure of the Report 977/65 that dealt with the conceptualization of graduate studies initiating the process of its institutionalization that followed with its regulation standardized by the Report $77 / 69$. In the third moment, it analyses the process of implementing postgraduate studies in Brazil, which has been configured as a new model superior to the two models from which it originated: the North American and the European.
\end{abstract}




\section{movim nto \\ programa de pós-graduação \\ faculdade de educação \\ ano 7 - número 14 - Edição Especial - 2020}

Following, it raises the problem of the risks of the disfiguration of the Brazilian postgraduate model represented by productivism, which leads to the examination of the productivity-quality dilemma in graduate studies, concluding with the presentation of strategies to avoid the disfiguration of the successful Brazilian experience post graduate.

Keywords: Brazilian Education. University. Postgraduate studies.

\section{MEDIO SIGLO DE POSGRADO EN BRASIL: DEL PERIODO HEROICO AL PRODUCTIVISMO POR LA MEDIACIÓN DE UN MODELO SUPERIOR A SUS MATRICES}

\section{RESUMEN}

A partir de la caracterización de la institución universitaria y su manifestación en Brasil, este artículo considera, en un primer momento, los antecedentes de los estudios de posgrado en Brasil y luego examina la estructura del Parecer 977/65 que abordó la conceptualización de los estudios de posgrado iniciando el proceso de su institucionalización que siguió con su regulación estandarizada por el Parecer 77/69. En el tercer momento, analiza el proceso de implantación de los estudios de posgrado en Brasil, que se configuró como un nuevo modelo superior a los dos modelos de los que se originó: el norteamericano y el europeo. A continuación, plantea el problema de los riesgos de la descaracterización del modelo de posgrado brasileño representados por el productivismo, lo que lleva al examen del dilema productividad-calidad en los estudios de posgrado, concluyendo con la presentación de estrategias para evitar la descaracterización de la experiencia exitosa brasileña de Posgrado.

Palabras clave: Educación brasileña. Universidad. Posgrado.

\section{Introdução}

Tendo surgido ao final do século XI de nossa era, a universidade assumiu a condição de corporação destinada à formação dos profissionais das artes intelectuais definindo-se como o espaço principal de desenvolvimento da pesquisa, o que se evidencia desde o século XVII nos seminários constituídos por grupos de estudantes que se reuniam em torno de um professor (SANTONI RUGIU, 1998. p. 109). Entre o final do século XVIII e início do século XIX a universidade se despiu de sua crosta medieval, dando origem à universidade moderna. Isso pode ser ilustrado com o caso da Universidade de Pádua que na última década do século XVIII era ainda "uma universidade medieval numa época moderna", vindo a se modernizar apenas com o domínio de Napoleão no então reino da Itália, entre 1805 e 1813 (GHETTI, 1982, p. 1-101, 214-312). 


\section{movim nto \\ programa de pós-graduação \\ f a culdade de educ a ção \\ ano 7 - número 14 - Edição Especial - 2020}

É também nesse momento que se configuram os três grandes modelos de universidade que se assentam nos elementos básicos constitutivos das universidades contemporâneas: o Estado, a sociedade civil e a autonomia da comunidade interna à instituição. Conforme prevaleça um ou outro, tem-se um diferente modelo institucional. A prevalência do Estado dá origem ao modelo napoleônico; prevalecendo a sociedade civil tem-se o modelo anglo-saxônico; e sobre a autonomia da comunidade acadêmica se funda o modelo humboldtiano. Este último modelo baseado na autonomia da comunidade interna, isto é, dos professores, propiciou o desenvolvimento mais intenso da pesquisa científica. Com a diáspora de cérebros provocada pelo nazismo, especialmente para os Estados Unidos, pode-se creditar ao modelo universitário dominante na Alemanha o impulso decisivo que se imprimiu ao desenvolvimento científico que se traduziu num sistema de pós-graduação diferenciado na universidade norteamericana. Pode-se, pois, dizer que a universidade, tal como a conhecemos atualmente, teve a sua configuração institucional definida na primeira metade do século XIX.

É lugar comum o entendimento de que a universidade no Brasil foi instituída tardiamente. Luiz Antônio Cunha (1986) em sua trilogia sobre a universidade no Brasil denomina o primeiro livro, que trata do ensino superior no período que se estende da Colônia à Era de Vargas, A Universidade temporã. Efetivamente "temporão" significa "fora do tempo apropriado".

A institucionalização da educação superior no Brasil, iniciada em 1808 com os cursos superiores criados por $\mathrm{D}$. João $\mathrm{VI}$, teve continuidade no Império com a criação das faculdades de direito. Na Primeira República ocorreu a criação de instituições livres, portanto, não oficiais. A partir da década de 1930 houve a retomada do protagonismo público que se acentuou nas décadas de 1940, 1950 e início dos anos 60 por meio da federalização de instituições estaduais e privadas e com a criação de novas universidades federais. Na fase da ditadura militar, a par do protagonismo público com destaque para a organização da pósgraduação, ocorreu certo estímulo à abertura de instituições privadas em 


\section{movim nto \\ rograma de pós-graduação \\ faculdade de educação \\ ano 7 - número 14 - Edição Especial - 2020}

especial na forma de faculdades isoladas. Mas em todo esse período iniciado com D. João VI e que se estendeu até a Constituição de 1988 detecta-se uma continuidade representada pela prevalência do modelo napoleônico de universidade na organização e expansão do ensino superior no Brasil.

A partir da década de 1990, num processo que está em curso nos dias atuais, emerge nova mudança caracterizada pela diversificação das formas de organização das instituições de ensino superior alterando-se o modelo de universidade na direção do modelo anglo-saxônico na versão norte-americana. Com isso, freou-se o processo de expansão das universidades públicas estimulando-se a expansão de instituições privadas sem e com fins lucrativos. Essa foi a política adotada nos oito anos do governo FHC.

Ao longo do governo Lula, se por um lado se retomou certo nível de investimento nas universidades federais com o Programa "REUNI", por outro lado deu-se continuidade ao estímulo à iniciativa privada recebendo alento adicional com o Programa "Universidade para todos", o PROUNI, destinado à compra de vagas em instituições privadas, o que veio a calhar diante do problema de vagas ociosas enfrentado por várias dessas instituições.

O avanço da privatização da educação superior está expresso nos índices quantitativos das instituições e do alunado chegando a uma relação de quatro instituições privadas para uma pública. No caso, porém, da pós-graduação essa relação se inverte manifestando-se uma clara supremacia das instituições públicas. Mas, como veremos, por meio do produtivismo também a pósgraduação vem sendo pressionada a submeter-se à lógica do mercado.

\section{Antecedentes da Pós-Graduação no Brasil}

Um marco importante na trajetória da educação superior no Brasil é o Decreto № 19.851, de 11 de abril de 1931 que, publicado em 15 de abril, colocou em vigência o Estatuto das Universidades Brasileiras. Podemos considerar que é com esse ato que a questão da universidade tem início oficialmente em nosso país. O referido Estatuto não faz referência à Pós-graduação. Mas, entre os "Fins 


\section{movim nto \\ programa de pós-graduação \\ faculdade de educação \\ ano 7 - número 14 - Edição Especial - 2020}

do Ensino Universitário" estabelecidos no Art. $1^{\circ}$ incluiu "estimular a investigação científica em quaisquer domínios dos conhecimentos humanos" (FÁVERO, 2000, p. 159); e estabeleceu no Art. 46 que, "[...] os institutos universitários deverão organizar e facilitar os meios para a realização de pesquisas originais, que aproveitem aptidões e inclinações, não só do corpo docente e discente, como de quaisquer outros pesquisadores..." (idem, p. 177). Ao tratar, no Título X, dos "Diplomas e Dignidades Universitárias", o Estatuto estipula, no Art. 90, a atribuição do título de doutor "quando após a conclusão dos cursos normais, técnicos ou científicos, e atendidas outras exigências regulamentares dos respectivos institutos, o candidato defender uma tese de sua autoria", explicitando, no $\S 1^{\circ}$. "A tese de que trata este artigo, para que seja aceita pelo respectivo instituto, deverá constituir publicação de real valor sobre assunto de natureza técnica ou puramente científica"; e, no $\S 2^{\circ}$ : "defesa de tese será feita perante uma comissão examinadora, cujos membros deverão possuir conhecimentos especializados da matéria" (idem, p. 188).

Vê-se que a via aberta pelo Estatuto segue a sistemática vigente nas universidades europeias que mantinham atividades de pesquisa, via de regra em seminários dirigidos pelos professores tendo, porém, como único instrumento de reconhecimento formal a concessão do título de doutor mediante defesa de tese sem a organização de cursos ou programas regulares de pós-graduação conducentes à obtenção dos títulos de mestre ou doutor.

Cabe, porém, fazer uma menção diferenciada à Escola Livre de Sociologia e Política de São Paulo. Criada em 1933, foi incorporada à USP como instituição complementar autônoma em 1939, mesmo ano em que passou a contar em seu quadro docente com o sociólogo norte-americano Donald Pierson que permaneceu até 1952 contribuindo fortemente para a consolidação da instituição. Assim, embora seu Estatuto não se refira a cursos de pós-graduação nem a concessões de títulos acadêmicos, nessas condições favoráveis foi criada, em 1941, a Divisão de Estudos Pós-Graduados que abrigou o primeiro Programa de Pós-Graduação em Ciências Sociais do Brasil. 


\section{movim nto \\ programa de pós-graduação \\ faculdade de educação \\ ano 7 - número 14 - Edição Especial - 2020}

Foi nesse Programa que Florestan Fernandes obteve o título de mestre com a pesquisa A organização social dos Tupinambá, publicada em 1949. Referências à Pós-Graduação e ao Doutorado passam a constar, também, nos artigos 71, 76 e 77 do Estatuto da Universidade do Brasil (atual UFRJ), aprovado em 18 de junho de 1946, assim como no artigo $9^{\circ}$ da Lei $n^{\circ} 3.998$, de 15 de dezembro de 1961, que criou a Universidade de Brasília (CURY, 2005, p. 8-9).

Enfim, nossa primeira Lei de Diretrizes e Bases da Educação Nacional (LDB), promulgada em 20 de dezembro de 1961, ao tratar, no Art. 69, dos cursos a serem ministrados nos estabelecimentos de ensino superior contemplou, na alínea b) os cursos "de pós-graduação, abertos a matrícula de candidatos que hajam concluído o curso de graduação e obtido o respectivo diploma". Eis aí o dispositivo que ensejou ao então Ministro da Educação e Cultura, Flávio Suplicy de Lacerda, o encaminhamento ao Conselho Federal de Educação de um Aviso Ministerial solicitando pronunciamento definindo e verificando a possibilidade de regulamentação dos mencionados cursos de pós-graduação. $E$ a resposta a esse aviso foi a elaboração e aprovação, pelo CFE, do Parecer n 977/65 relatado pelo Conselheiro Newton Sucupira aprovado em 3 de dezembro de 1965, homologado pelo ministro em 6 de janeiro de 1966 e publicado no Diário Oficial da União em 20 de janeiro de 1966. Tinha início, aí, o processo de institucionalização, em âmbito nacional, dos estudos pós-graduados no Brasil.

\section{Estrutura do Parecer $n^{\circ} 977 / 65$}

Com o título "Definição dos Cursos de Pós-Graduação" o parecer, após uma introdução em que se reporta ao Aviso do ministro, desenvolve os seguintes tópicos:

\subsection{Origem histórica da pós-graduação}

Conforme o Parecer tanto o nome "pós-graduação" como o "sistema" se originam na estrutura da universidade norte-americana que compreende 0 "college" ou "Undergraduate School", que corresponde à nossa Graduação, 


\section{movim nto \\ programa de pós-graduação \\ faculdade de educação \\ ano 7 - número 14 - Edição Especial - 2020}

e a "Graduate School", correspondente à nossa pós-graduação. E destaca que a pós-graduação nos Estados Unidos é produto da influência alemã representando a culminância da ascendência germânica sobre a universidade norte-americana.

\subsection{Necessidade da pós-graduação}

A necessidade da pós-graduação decorre do enorme desenvolvimento da ciência em todos os seus ramos tornando impossível seu domínio apenas nos cursos de graduação. Manifesta-se, pois, em todos os países a tendência a introduzir os estudos pós-graduados, observando-se que a França não se refere a graduação e pós-graduação, mas organiza o ensino superior em três ciclos escalonados sendo que o terceiro ciclo é o do doutorado. Por fim, o parecer destaca que no Brasil os cursos de pós-graduação "quase não existem" em funcionamento regular impondo-se, pois, a urgência de sua implantação.

\subsection{Conceito de pós-graduação}

Para conceituar a pós-graduação o parecer começa por distinguir entre a pós-graduação lato sensu e stricto sensu para concluir que a pós-graduação stricto sensu é de "natureza acadêmica e de pesquisa", enquanto a lato sensu "tem sentido eminentemente prático-profissional"; a stricto sensu "confere grau acadêmico" e a lato sensu "concede certificado". E apresenta a seguinte definição da pós-graduação em sentido estrito: "o ciclo de cursos regulares em seguimento à graduação, sistematicamente organizados, visando desenvolver e aprofundar a formação adquirida no âmbito da graduação e conduzindo à obtenção de grau acadêmico".

\subsection{Um exemplo de pós-graduação: a norte-americana}

Considerando incipiente nossa experiência de pós-graduação o parecer vai buscar orientação na experiência norte-americana constatando a distinção entre mestrado e doutorado como dois níveis que, embora hierarquizados são 


\section{movim nto \\ programa de pós-graduação \\ faculdade de educação \\ ano 7 - número 14 - Edição Especial - 2020}

relativamente autônomos não sendo, pois, o mestrado pré-requisito indispensável para o doutorado. Dessa forma, pode haver carreiras, como a de medicina que, nos Estados Unidos, têm doutorado, mas não têm mestrado. $E$, obviamente, é possível obter o título de mestre como grau terminal sem ascender ao nível do doutorado. Tanto o mestrado como o doutorado implicam estudos e exames que se estendem num tempo bem mais longo do que a graduação e, para ingresso, há rigorosa seleção intelectual. No doutorado sempre se exige tese. No caso do mestrado pode-se exigir dissertação, memória ou ensaio, ou podem ser considerados suficientes os exames prestados. De qualquer modo, tanto para o mestrado como para o doutorado além da tese ou da dissertação, memória ou ensaio são exigidos certo número de cursos, participação em seminários e pesquisas e uma série de exames, incluído o de suficiência em línguas estrangeiras. Mas em todas as atividades o estudante terá sempre a assistência e orientação de um professor.

\subsection{A pós-graduação na Lei de Diretrizes e Bases}

Após delinear as características da pós-graduação o parecer passa a tratar do disposto nessa matéria na Lei de Diretrizes e Bases, o que se consubstancia no artigo 69 em que se distinguem três categorias de cursos:

a) graduação, abertos à matrícula de candidatos que hajam concluído o ciclo colegial ou equivalente, e obtido classificação em concurso de habilitação;

b) pós-graduação, abertos à matrícula de candidatos que hajam concluído o curso de graduação e obtido o respectivo diploma;

c) especialização, aperfeiçoamento e extensão, ou quaisquer outros, a juízo do respectivo instituto de ensino abertos a candidatos com o preparo e os requisitos que vierem a ser exigidos.

Analisando esse ponto Newton Sucupira entende que o disposto na letra b) corresponde à pós-graduação stricto sensu, uma vez que se limita a candidatos que já concluíram a graduação enquanto que os cursos de especialização, aperfeiçoamento e extensão, previstos na alínea c), não necessariamente implicam a conclusão da graduação. 


\section{movim nto \\ programa de pós-graduação \\ faculdade de educação \\ ano 7 - número 14 - Edição Especial - 2020}

\subsection{A pós-graduação e o Estatuto do Magistério}

Considerando, por um lado, o Aviso Ministerial que pedia ao CFE a definição dos Cursos de Pós-Graduação previstos pela LDB e também sua regulamentação e, por outro lado, seu próprio entendimento de que a regulamentação resulta necessária sob pena do "abastardamento inevitável dos graus de Mestre e Doutor"; e tendo em vista que o artigo 70 da LDB limitava a regulamentação aos cursos que conferem privilégio para o exercício de profissão liberal, o relator recorre, então, ao Estatuto do Magistério que, pelo artigo 25, incumbia o CFE de, no prazo de 60 dias, conceituar e fixar as características dos cursos de pós-graduação. Com base nessa incumbência uma certa regulamentação poderia ser estabelecida.

\subsection{Definição e características do Mestrado e Doutorado}

Por fim, atendendo ao Aviso Ministerial e à determinação do Estatuto do Magistério, Newton Sucupira conclui seu parecer definindo e fixando as características dos cursos de Mestrado e Doutorado. Esclarece que se trata de indicar apenas as balizas mestras para não prejudicar a necessária flexibilidade própria da pós-graduação tendo em vista preservar a margem de iniciativa da instituição e do aluno na organização de seus estudos. E, após algumas considerações, enfeixa o resultado do Parecer em dezesseis conclusões que, a seguir, são integralmente transcritas:

1) A pós-graduação de que trata a alínea b do art. 69 da Lei de Diretrizes e Bases é constituída pelo ciclo de cursos regulares em seguimento à graduação e que visam a desenvolver e aprofundar a formação adquirida nos cursos de graduação e conduzem à obtenção de grau acadêmico.

2) A pós-graduação compreenderá dois níveis de formação: Mestrado e Doutorado. Embora hierarquizados, o mestrado não constitui condição indispensável à inscrição no curso de doutorado.

3) O mestrado pode ser encarado como etapa preliminar na obtenção do grau de doutor ou como grau terminal.

4) O doutorado tem por fim proporcionar formação científica ou cultural ampla e aprofundada, desenvolvendo a capacidade de pesquisa e poder criador nos diferentes ramos do saber. 


\section{movimento \\ revista de educação do \\ programa de pós-graduação \\ faculdade de educação \\ ano 7 - número 14 - Edição Especial - 2020}

5) O doutorado de pesquisa terá a designação das seguintes áreas: Letras, Ciências Naturais, Ciências Humanas e Filosofia; os doutorados profissionais ${ }^{1}$ denominam-se segundo os cursos de graduação correspondentes. O mestrado será qualificado pelo curso de graduação, área ou matéria a que se refere.

6) Os cursos de mestrado e doutorado devem ter a duração mínima de um e dois anos respectivamente. Além do preparo da dissertação ou tese, o candidato deverá estudar certo número de matérias relativas à sua área de concentração e ao domínio conexo, submeter-se a exames parciais e gerais, e provas que verifiquem a capacidade de leitura em línguas estrangeiras. Pelo menos uma para o mestrado e duas para o doutorado.

7) Por área de concentração entende-se o campo específico de conhecimento que constituirá o objeto de estudos escolhido pelo candidato, e por domínio conexo qualquer matéria não pertencente àquele campo, mas considerada conveniente ou necessária para completar sua formação.

8) O estabelecimento deve oferecer um elenco variado de matérias a fim de que o candidato possa exercer sua opção. As matérias, de preferência, serão ministradas sob a forma de cursos monográficos dos quais, seja em preleções, seja em seminários, o professor desenvolverá, em profundidade, um assunto determinado.

9) Do candidato ao Mestrado exige-se dissertação, sobre a qual será examinado, em que revele domínio do tema escolhido e capacidade de sistematização; para o grau de Doutor requer-se defesa de tese que represente trabalho de pesquisa importando em real contribuição para o conhecimento do tema.

10) O programa de estudos do Mestrado e Doutorado se caracterizará por grande flexibilidade, deixando-se ampla liberdade de iniciativa ao candidato que receberá assistência e orientação de um diretor de estudos. Constará o programa, sobretudo, de seminários, trabalhos de pesquisa, atividades de laboratório com a participação ativa dos alunos.

11) O mesmo curso de pós-graduação poderá receber diplomados provenientes de cursos de graduação diversos, desde que apresentem certa afinidade. Assim, por exemplo, ao mestrado ou doutorado em Administração Pública poderiam ser admitidos bacharéis em Direito ou Economia; em Biologia, Médicos ou diplomados em História Natural.

12) Para matrícula nos cursos de pós-graduação, além do diploma do curso de graduação exigido por lei, as instituições poderão estabelecer requisitos que assegurem rigorosa seleção intelectual dos candidatos. Se os cursos de graduação devem ser abertos ao maior número, por sua natureza, a pósgraduação há de ser restrita aos mais aptos.

13) Nas Universidades a pós-graduação de pesquisa ou acadêmica deve ser objeto de coordenação central, abrangendo toda área das ciências e das letras, inclusive das que fazem parte do ciclo básico das faculdades profissionais.

14) Conforme o caso, aos candidatos ao doutorado serão confiadas tarefas docentes, sem prejuízo do tempo destinado aos seus estudos e trabalhos de pesquisa.

15) Aconselha-se que a pós-graduação se faça em regime de tempo integral, pelo menos no que se refere à duração mínima dos cursos.

\footnotetext{
${ }^{1}$ Essa denominação não se refere à especialização profissional como nos atuais mestrados profissionais. Trata-se da produção de pesquisas em áreas de profissões liberais. Os exemplos mencionado no Parecer são:" Doutor em Engenharia, Doutor em Medicina etc.".
} 


\section{movim nto \\ programa de pós-graduação \\ faculdade de educação \\ ano 7 - número 14 - Edição Especial - 2020}

16) Os cursos de pós-graduação devem ser aprovados pelo Conselho federal de Educação para que seus diplomas sejam registrados no Ministério da Educação e possam produzir efeitos legais. Para isso o Conselho baixará normas fixando os critérios de aprovação dos cursos (BRASIL, 1965, p. 84-86).

Essas conclusões se configuram, de fato, como balizas mestras indicativas da forma como deve ser regulamentada a implantação da pósgraduação no Brasil. Assim, esse Parecer n 977/65 é, sem dúvida, o marco inicial da institucionalização da pós-graduação no Brasil. Sua importância é, pois, inegável, a ponto de ser geralmente considerado como o "texto fundador da pósgraduação sistemática no Brasil" (CURY, 2005, p. 18). Mas a regulamentação propriamente dita ocorreu com o Parecer CFE $n^{\circ} 77 / 69$, também de autoria de Newton Sucupira, aprovado em 11 de fevereiro de 1969, que estabeleceu as "Normas do Credenciamento dos Cursos de Pós-Graduação", explicitando no parágrafo único do artigo $1^{\circ}$ : "Os cursos de pós-graduação de que tratam as presentes normas são aqueles que conferem os graus de Mestre e Doutor na forma definida pelo Parecer $n^{\circ}$ 977/65 do C.F.E.". Após indicar a documentação que deve acompanhar o pedido de credenciamento e as condições de edificação, capacidade financeira, a comprovação da alta qualificação do corpo docente, os recursos e equipamentos conforme a natureza dos cursos, a existência de biblioteca atualizada e selecionada, são retomadas com alguma variação e atualização terminológica, no artigo 13, em doze incisos, as conclusões do Parecer n 977/65. O artigo 15 prevê a constituição de comissão de especialistas para verificação in loco das condições de funcionamento do curso a ser credenciado. E o artigo 17 determina que o credenciamento terá validade de cinco anos, cabendo renovação.

Vê-se, pois, que o objeto próprio do Parecer n 977/65 foi a conceituação da pós-graduação enquanto o objeto do Parecer $n^{\circ} 77 / 69$ foi a regulamentação da implantação da pós-graduação. A partir daí e ao longo da década de 1970 desencadeou-se o processo de abertura e expansão dos programas de pósgraduação no Brasil, constituindo-se no período heroico, pois as condições de infraestrutura e os materiais bibliográficos eram providenciados ao mesmo 


\section{movimento \\ programa de pós-graduação \\ faculdade de educação \\ ano 7 - número 14 - Edição Especial - 2020}

tempo em que se abriam os programas e se iniciavam as atividades de pósgraduação.

\section{A pós-graduação e sua configuração no Brasil: um novo modelo ${ }^{2}$ ?}

Sobre a conceituação da pós-graduação cabe recordar que os cursos de pós-graduação são entendidos, literalmente, como aqueles que se realizam após a graduação. Vê-se, então, que Sucupira, no Parecer n 977/65, reconheceu a distinção entre pós-graduação lato sensu e stricto sensu e interpretou a alínea c) do artigo 69 da LDB n 4.024/61 ("cursos de especialização, aperfeiçoamento e extensão ou quaisquer outros") como correspondendo ao lato sensu que, na norma da LDB, não estaria exigindo a conclusão da graduação. Ora, então não se trataria de cursos de pós-graduação. Cumpre, então, observar que é possível oferecer cursos de especialização, aperfeiçoamento e extensão na forma de pós-graduação ou não. No caso de serem de pós-graduação serão abertos a candidatos que tenham concluído a graduação e incidirão na modalidade lato sensu. No contexto brasileiro tornou-se corrente a distinção entre a pósgraduação lato sensu e a pós-graduação stricto sensu.

Os cursos de pós-graduação lato sensu assumem dominantemente as formas de aperfeiçoamento e especialização e constituem uma espécie de prolongamento da graduação, pois visam a um aprimoramento (aperfeiçoamento) ou aprofundamento (especialização) da formação profissional obtida no curso de graduação correspondente.

A pós-graduação stricto sensu, organizada sob as formas de mestrado e doutorado, possui um objetivo próprio, distinto daquele da graduação sendo, por isso mesmo, considerada como a pós-graduação propriamente dita. Nessa condição, diferentemente dos cursos de graduação que estão voltados para a formação profissional, a pós-graduação stricto sensu se volta para a formação acadêmica voltada ao objetivo da formação de pesquisadores.

\footnotetext{
${ }^{2} \mathrm{Na}$ redação deste tópico retomo aspectos de estudos anteriores (SAVIANI, 2014, p. 134-141). 


\section{movim nto \\ programa de pós-graduação \\ faculdade de educação \\ ano 7 - número 14 - Edição Especial - 2020}

Portanto, a pós-graduação lato sensu tem como elemento definidor o ensino, pois é este que determina o objetivo a ser alcançado, entrando a pesquisa como mediação para se atingir o objetivo preconizado. Em contraposição, o elemento definidor da pós-graduação stricto sensu é a pesquisa, a qual determina o objetivo a ser alcançado para o qual o ensino concorre como uma mediação destinada a dispor os requisitos para o desenvolvimento da pesquisa que será a pedra de toque da formação pretendida.

Em razão do acima exposto é que se deu preferência ao termo programa em lugar de curso para a pós-graduação stricto sensu. A razão dessa distinção reside no fato de que o termo curso se liga diretamente ao ensino e seu centro é um elenco de disciplinas que os alunos devem cursar. Ora, essa é a característica específica da pós-graduação lato sensu. Em contrapartida, a pósgraduação stricto sensu, além do ensino envolve, como elemento central, a pesquisa. Daí, a adoção do termo programa para abarcar tanto as atividades de ensino como de pesquisa.

A referida distinção foi também consagrada no texto da nova LDB, de 20/12/1996, que reserva o termo programa para a pós-graduação stricto sensu, utilizando o termo curso para a pós-graduação lato sensu, conforme estipulado no artigo 44:

A educação superior abrangerá os seguintes cursos e programas: I - cursos sequenciais...; II - de graduação...; III - de pós-graduação, compreendendo programas de mestrado e doutorado, cursos de especialização, aperfeiçoamento e outros, abertos a candidatos diplomados em cursos de graduação e que atendam às exigências das instituições de ensino (negritos meus). (BRASIL, 1996)

Observe-se que nessa LDB já não há a ambiguidade que constava na alínea c) do artigo 69 da LDB anterior, pois na LDB atual, tanto para os "programas de mestrado e doutorado" como para os "cursos de especialização, aperfeiçoamento e outros", consta explicitamente que são abertos a candidatos diplomados em "cursos de graduação". 


\section{movim nto \\ programa de pós-graduação \\ faculdade de educação \\ ano 7 - número 14 - Edição Especial - 2020}

Entende-se, então, que a proposta de um curso de aperfeiçoamento ou especialização se justifica em consequência do avanço do conhecimento decorrente do desenvolvimento da pesquisa na área em questão, cujos resultados afetam o perfil da profissão correspondente. Nesse caso o curso de pós-graduação lato sensu se proporá a garantir a assimilação dos procedimentos ou resultados do avanço da pesquisa, por parte dos profissionais da área em referência, ajustando o seu perfil às mudanças operadas no perfil da sua profissão. Os programas de pós-graduação stricto sensu, por sua vez, se justificam tendo em vista o próprio avanço do conhecimento, isto é, o desenvolvimento das pesquisas numa área determinada, contribuindo diretamente para essa finalidade.

Esclarecida a questão conceitual resumo, a seguir, o modo como se configurou a pós-graduação no Brasil.

O modelo de pós-graduação adotado no Brasil seguiu deliberadamente a experiência dos Estados Unidos, como foi evidenciado no texto do Parecer 977/65. É com base nessa experiência que se definiu a estrutura organizacional da nossa pós-graduação stricto sensu centrada em dois níveis, o mestrado e o doutorado. Cada um desses níveis compreenderia o estudo de um conjunto de matérias relativas tanto à área de concentração, isto é, o campo de estudos escolhido pelo candidato, como ao domínio conexo, ou seja, a área de conhecimento complementar àquela escolhida pelo aluno. O programa de estudos deveria se completar com a redação de um trabalho resultante de pesquisa, a dissertação, para o mestrado, e a tese, para o doutorado. Assim, a organização dos estudos resulta bastante clara com tarefas bem especificadas prevendo, inclusive, a figura de um orientador para cada um dos alunos.

Entretanto, se a estrutura organizacional se inspirou no modelo americano, o espírito com que se deu a implantação dos programas foi em grande parte influenciado pela experiência europeia.

É interessante observar que nos Estados Unidos prevalecia na educação básica, sob a influência do ideário da pedagogia nova, o objetivo de socialização 


\section{movim nto \\ programa de pós-graduação \\ faculdade de educação \\ ano 7 - número 14 - Edição Especial - 2020}

das crianças e jovens justificado pelo discurso do incentivo à autonomia e iniciativa dos alunos, ficando em segundo plano o domínio dos conhecimentos sistematizados; e no nível superior, os alunos tendiam a ser postos diante de uma organização bastante definida com tarefas orientadas pelos docentes. Inversamente, na Europa, os sistemas de educação básica foram organizados sob a concepção tradicional herdada do iluminismo que colocava como objetivo principal o domínio dos conhecimentos sistematizados; em consequência, tendia-se a se esperar dos alunos que ingressavam na universidade um grau de maturidade e de autonomia intelectual que dispensava, por parte dos professores, uma direção ou mesmo uma orientação mais direta. E, especialmente na pós-graduação, que era constituída fundamentalmente pelo doutorado, esperava-se que os candidatos concebessem e realizassem por si mesmos o próprio trabalho sendo o orientador mais um examinador e o presidente das bancas de exame do que alguém que dirigia e interferia diretamente na definição e desenvolvimento do tema de estudo do doutorando. Assim, enquanto a experiência universitária norte-americana põe uma certa ênfase no aspecto técnico-operativo, na experiência europeia a ênfase principal recai sobre o aspecto teórico.

Sabemos do peso da influência europeia sobre os intelectuais brasileiros, em especial na área das chamadas ciências humanas. E esse dado é importante para entendermos a tendência que acabou por prevalecer na pós-graduação brasileira. Com efeito, a implantação da pós-graduação se deu a partir do mestrado. E, embora os alunos devessem cursar determinadas disciplinas, os professores, via de regra, supunham um razoável grau de autonomia dos mestrandos esperando que eles definissem o próprio objeto de investigação e, ato contínuo, escolhessem o orientador adequado para acompanhá-lo em sua pesquisa. Este é um dos fatores explicativos do longo tempo destinado à realização do mestrado ligado à expectativa de que os alunos deveriam produzir um trabalho de fôlego, na prática equivalente a uma tese de doutorado. Isso não causou grandes problemas na fase inicial quando, diante da demanda reprimida 


\section{movim nto \\ programa de pós-graduação \\ faculdade de educação \\ ano 7 - número 14 - Edição Especial - 2020}

e não existindo ainda o doutorado, acediam ao mestrado professores já com razoável maturidade intelectual e uma boa experiência no magistério superior. Passada, porém, essa primeira fase foi se constatando em escala cada vez mais generalizada que, enquanto o orientador esperava que o próprio aluno escolhesse de modo autônomo o tema de sua dissertação, formulasse o problema, definisse o enfoque teórico, delimitasse o objeto e estabelecesse a metodologia e respectivos procedimentos de análise, o mestrando se sentia sem rumo e despendia muito tempo sem corresponder a essas expectativas do orientador, o que o fazia buscar o socorro de outros professores, enveredar pelas mais desencontradas leituras ou observações de campo até conseguir encontrar, mas após muito dispêndio de energia e de tempo, o objeto de estudo que daria origem à sua dissertação de mestrado.

É diante desse quadro que surgiram as pressões pela redução do tempo com a tendência a secundarizar o mestrado, dispensar a exigência de dissertação ou, mesmo, eliminar essa etapa da pós-graduação stricto sensu. Entendo que esse encaminhamento pode pôr em risco a particularidade da pósgraduação brasileira que lhe permitiu se constituir numa das mais ricas e consistentes experiências de pós-graduação. E essa riqueza advém, acredito, da fusão entre uma estrutura organizacional bastante articulada, derivada da influência americana, e o empenho em se garantir um grau satisfatório de densidade teórica, decorrente da influência europeia. Para evitar o risco apontado preservando a particularidade da experiência brasileira cumpre manter presente a especificidade da pós-graduação stricto sensu, cujo objetivo é a formação de pesquisadores.

Ora, se o objetivo precípuo da pós-graduação stricto sensu é a formação do pesquisador, o elemento central em torno do qual ela deve ser organizada é a pesquisa. E como a pós-graduação stricto sensu está organizada em dois níveis, mestrado e doutorado, conclui-se que o primeiro nível tem o sentido de iniciação à formação do pesquisador, reservando-se ao segundo nível a função de consolidação. 


\section{movim nto \\ programa de pós-graduação \\ faculdade de educação \\ ano 7 - número 14 - Edição Especial - 2020}

Assim, embora seja desejável que a iniciação se dê já no nível da graduação, não parece razoável inscrevê-la como uma exigência obrigatória já nessa primeira etapa do ensino superior. A chamada iniciação científica nos cursos de graduação tem a finalidade de familiarizar o aluno (o futuro profissional) com a investigação científica, o que não implica a realização, por parte de cada um dos alunos, de um projeto próprio e completo de investigação.

No caso do mestrado, porém, a iniciação requerida será feita mediante a realização de um trabalho completo de investigação. Para a maioria dos alunos será, de fato, o primeiro trabalho de pesquisa que ele cumpre, abarcando todas as etapas implicadas no tipo de investigação encetada, culminando com a redação da dissertação com uma estrutura lógica adequada à compreensão plena, por parte dos leitores, do assunto tratado.

Assim entendida, a dissertação de mestrado supõe um trabalho relativamente simples, expresso num texto logicamente articulado dando conta de um determinado tema. Distingue-se de tese, denominação reservada ao trabalho do doutorado, já que tese significa posição, sugerindo que a defesa de uma tese é a defesa de uma posição diante de determinado problema. A tese pressupõe, em consequência, os requisitos de autonomia intelectual e de originalidade, já que estas são condições para que alguém possa expressar uma posição própria sobre determinado assunto. Ora, tais requisitos não são exigidos no caso do mestrado. Supõe-se, antes, que é a conclusão do mestrado que propiciará o preenchimento desses requisitos, uma vez que, tendo realizado, com o apoio do orientador, um trabalho completo de investigação, esse exercício Ihe permitirá adquirir um domínio teórico e prático do processo, atingindo, assim, a desejada autonomia intelectual que Ihe facultará a formulação original de novos objetos de investigação. Dessa forma, enquanto para o mestrado a autonomia intelectual e a originalidade constituem ponto de chegada, para o doutorado esses requisitos se põem no ponto de partida como condições prévias para a realização da etapa final do processo de formação do pesquisador. 


\section{movim nto \\ programa de pós-graduação \\ faculdade de educação \\ ano 7 - número 14 - Edição Especial - 2020}

Em suma: considerando-se que a pós-graduação stricto sensu destina-se à formação do pesquisador; considerando-se que o mestrado tem a incumbência de efetivar a iniciação dos alunos tendo em vista a assunção, por parte deles, da condição de pesquisadores; considerando-se que essa iniciação implica a realização de um trabalho completo de investigação, conclui-se ser inconcebível um mestrado sem dissertação.

À vista do exposto, entendo que pretender a redução do tempo de realização do mestrado abrindo mão da dissertação é obter a redução ao preço da sua descaracterização. É necessário, pois, afastar certas alternativas que, tendo em vista o objetivo de redução do tempo de formação, acenam com a organização de cursos de mestrado sem dissertação, a exemplo do que ocorre nos Estados Unidos. Em verdade, esse tipo de mestrado se descaracterizaria como pós-graduação stricto sensu, sendo assimilado aos cursos de especialização, integrantes da pós-graduação lato sensu, já que tenderia a subordinar a formação acadêmica à formação profissional, abrindo mão do objetivo de formação de pesquisadores. Aliás, ao que parece, é exatamente a admissão de uma distinção entre uma espécie de mestrado profissional e um mestrado acadêmico que explica a existência, nos EEUU, de um mestrado sem dissertação ao lado do mestrado com dissertação. Cabe, pois, considerar que, no caso brasileiro, a alternativa para mestrado com dissertação não seria o mestrado sem dissertação nem mesmo o mestrado profissional, ainda que com dissertação, mas os cursos de especialização.

Trata-se, então, de definir o tempo necessário à realização do mestrado a partir da compreensão de sua natureza e objetivos e não o contrário. E desde que, como se mostrou, o ponto central do mestrado consiste na dissertação, é a partir do dimensionamento do tempo necessário à realização da dissertação que cabe definir o tempo de duração do mestrado. E esse tempo só poderá ser definido na medida em que se dispuser de algum critério de caracterização da própria dissertação. $E$ foi na busca de tal critério que elaborei o texto $A$ monografia de base como ideia reguladora da dissertação de mestrado 


\section{movim nto \\ programa de pós-graduação \\ faculdade de educação \\ ano 7 - número 14 - Edição Especial - 2020}

(SAVIANI, 1991). A ideia era pensar as dissertações como incidindo sobre temas relevantes ainda não suficientemente explorados, cabendo ao mestrando a tarefa de realizar um levantamento, o mais completo possível, das informações disponíveis, organizá-las segundo critérios lógico-metodológicos adequados e redigir o texto correspondente que permitiria o acesso ágil ao assunto tratado. A existência dessas monografias de base possibilitaria a um pesquisador mais experiente realizar, a partir das informações primárias já devidamente organizadas, sínteses de amplo alcance que seriam inviáveis ou demandariam um tempo excessivo sem esse trabalho preliminar das monografias de base.

Essa proposta supunha que o corpo docente identificasse os temas, os enfoques e os momentos da educação brasileira que se encontram em aberto, estabelecendo um amplo programa de produção de monografias de base no qual seriam engajados os estudantes de mestrado para efeitos de elaboração de suas dissertações, com o que eles estariam se iniciando como pesquisadores dando, ao mesmo tempo, uma contribuição para o avanço do conhecimento no campo educacional. Como se vê, a proposta implica a existência de linhas de pesquisa nas quais os docentes desenvolvem, de forma articulada, projetos próprios de pesquisa. Como a prática que prevalecia era a de que os docentes, após a realização de sua pesquisa de doutorado passassem a orientar as pesquisas dos alunos sem, porém, desenvolver projetos próprios, resultava difícil a implantação do programa de produção de monografias de base tal como fora proposto. Paradoxalmente, na situação atual quando as referidas condições já vêm sendo preenchidas com a criação, na maioria dos programas, de grupos de pesquisa e o desenvolvimento, pelos docentes, de projetos próprios de pesquisa, aquela proposta está esquecida e é a existência mesma do mestrado, enquanto pós-graduação stricto sensu, que se encontra ameaçada.

A estratégia da produção de monografias de base em cada programa de pós-graduação seria uma forma simples de assegurar, para a maioria dos alunos, a iniciação de sua formação como pesquisadores já que ofereceria alternativas precisas para a realização das dissertações, poupando-lhes tempo 


\section{movim nto \\ programa de pós-graduação \\ faculdade de educação \\ ano 7 - número 14 - Edição Especial - 2020}

e energia ao envolvê-los de imediato num processo real de investigação. Com o tema da dissertação definido desde o início, resultaria possível dimensionar o tempo de duração do mestrado que em princípio se situaria na faixa dos três anos. Dado o seu caráter de iniciação que envolve a necessidade de cursar disciplinas, considero não ser viável nem desejável reduzir o tempo para aquém do prazo indicado. Entretanto, concluída com êxito essa etapa de iniciação, o doutorado poderia estar concentrado fortemente na realização da pesquisa o que viabilizaria a sua conclusão, como a experiência tem demonstrado, num prazo de 30 a 36 meses. Com isso o tempo total da formação do pesquisador giraria em torno de cinco a seis anos, prazo que fatalmente acabaria sendo destinado ao doutorado se, na hipótese de extinção do mestrado, a ele fosse atribuído todo o processo de formação do pesquisador.

Equacionando-se a questão do tempo pela via de uma consistente organização dos estudos seria possível preservar e, mesmo, aprofundar e fortalecer a rica experiência da pós-graduação brasileira. Esta, fundindo a estrutura organizacional do modelo americano com a densidade teórica resultante da influência europeia, produziu um modelo novo, com certeza superior àqueles que lhe deram origem. Essa perspectiva, entretanto, não se delineia com clareza no horizonte da nossa pós-graduação. Ao contrário, a situação atual alberga a tendência de desarticulação da experiência bem sucedida de estudos pós-graduados em nosso país que resulta ameaçada pela pressão para a redução dos prazos, exercida de modo especial sobre o mestrado pela exigência de produtividade. Tais pressões nos colocam diante de um verdadeiro dilema quando nos empenhamos na busca de qualidade na pósgraduação. Devemos considerar, pois, em que consiste e como se manifesta esse dilema.

\section{O dilema produtividade-qualidade na pós-graduação ${ }^{3}$}

\footnotetext{
${ }^{3} \mathrm{Na}$ redação deste tópico retomo aspectos de análises anteriores (SAVIANI, 2019, p. 12-15 e 323-325).
} 


\section{movim nto \\ programa de pós-graduação \\ faculdade de educação \\ ano 7 - número 14 - Edição Especial - 2020}

Considerando-se o caráter da atividade científica e da educação como modalidades de produção não-material cujo produto não se separa do ato de produção; que a pesquisa, enquanto atividade científica, e a formação do pesquisador, enquanto atividade educativa, participam dessa característica; que a compatibilidade entre a busca de produtividade e a busca da qualidade supõe a plena objetivação do processo de trabalho; que a produção não-material não é suscetível de plena objetivação, segue-se que, nas condições próprias da produção não-material, a busca da produtividade entra em contradição com a qualidade dos resultados dessa produção. Está aí a raiz do dilema produtividadequalidade nos programas de pós-graduação, isto é, no desenvolvimento da pesquisa e na formação do pesquisador.

Dilema é um termo derivado do grego ( $\left.\delta{ }_{1} \lambda \eta \mu \mu \alpha\right)$ que tem o sentido de uma argumentação com duas conclusões contraditórias igualmente possíveis logicamente, generalizando-se o significado de dilema como uma situação embaraçosa com duas saídas igualmente difíceis. Vê-se, pois, que, quando falamos do dilema produtividade-qualidade na pós-graduação estamos falando de uma situação embaraçosa, pois o incremento da produtividade interfere negativamente na qualidade e vice-versa. Assim, ambos os caminhos revelamse igualmente difíceis, pois não se pode abrir mão da qualidade, mas também não se pode descuidar da produtividade. Ocorre que esse sentimento incide naquela "estreiteza mental burguesa", referida por Marx, que se contenta em considerar produtivo todo trabalho que produz alguma coisa, o que não passa de uma tautologia, pois leva à conclusão que trabalho improdutivo é aquele que nada produz. Assim, resulta evidente que os Programas de Pós-Graduação não podem abrir mão da produtividade, pois isso significaria admitir que ficariam improdutivos, vale dizer, sem produzir coisa alguma. Daí, as classificações tautológicas dos processos de avaliação que chegam a conclusões do seguinte tipo: determinado Programa é muito produtivo porque produz muito; outro é pouco produtivo, pois produz pouco; um terceiro é muito pouco produtivo porque produz muito pouco, e assim sucessivamente. Mas, trabalho produtivo, na 


\section{movim nto \\ programa de pós-graduação \\ faculdade de educação \\ ano 7 - número 14 - Edição Especial - 2020}

sociedade capitalista em que vivemos é aquele que gera mais-valia; e trabalho improdutivo é o que não gera mais-valia o que, evidentemente, não significa que nada produza.

Como esclarece Marx, o trabalho produtivo corresponde ao circuito D-MD' (Dinheiro-Mercadoria-Capital), isto é, uma situação em que se troca mercadoria por dinheiro enquanto capital, ou seja, a mercadoria é meio para aumentar o capital, para lhe acrescentar valor; ao passo que o trabalho improdutivo corresponde ao circuito M-D-M (Mercadoria-Dinheiro-Mercadoria) em que se troca mercadoria por dinheiro enquanto dinheiro, isto é, o dinheiro obtido pela venda de terminada mercadoria é meio para se adquirir outra mercadoria que venha a satisfazer determinada necessidade de consumo do comprador, não entrando no circuito do capital.

À luz das considerações feitas, resulta claro que o manejo do conceito de produtividade no campo da pesquisa e da pós-graduação significa colocá-las sob a órbita do capital. E isto é compreensível, pois "o capital é a força econômica da sociedade burguesa que tudo domina" (MARX, 1973, p. 236) o que faz com que, nesse tipo de sociedade, tudo tende a cair sob a lógica do capital.

Não obstante essa constatação, não se pode desconsiderar o fato de que se trata de um processo contraditório que, no caso em tela, coloca em campos opostos a produtividade e a qualidade da pesquisa e da formação pós-graduada: a exigência de produtividade dificulta a realização da qualidade e a ênfase na qualidade não se enquadra nos critérios de mensuração da produtividade.

O dilema consiste em que se admite que os dois aspectos, a produtividade e a qualidade, devam integrar o processo de pesquisa e de formação de pesquisadores, mas não sabemos como articulá-los nem qual o peso específico que cada um deles deve ter no referido processo. E quando vislumbramos alguma perspectiva de solução em nível institucional, defrontamo-nos com duas saídas igualmente embaraçosas. Com efeito, poderíamos dar precedência ao primeiro aspecto e, nesse caso, nos esforçaríamos em atender aos critérios da CAPES e das agências de apoio à pesquisa e à pós-graduação. Assim 


\section{movim nto \\ programa de pós-graduação \\ faculdade de educaçã o \\ ano 7 - número 14 - Edição Especial - 2020}

procedendo, todas as energias da coordenação e corpo docente dos programas de pós-graduação e dos grupos de pesquisa a eles ligados se dirigiriam, por um lado, a aumentar o número de relatórios de pesquisa, encontrar mecanismos de transformá-los em trabalhos apresentados em eventos científicos ou publicados em artigos, livros e capítulos de livros e, por outro lado, a reduzir o tempo destinado à produção de dissertações e teses. Com isso, passariam para segundo plano a relevância, pertinência e consistência dos trabalhos produzidos.

A consequência seria a queda crescente da qualidade dos Programas de Pós-Graduação. Ou, por outra, poderíamos, dando precedência ao segundo aspecto, voltar todas as atenções e cuidados para o aprimoramento da qualidade, situação em que ficariam em plano subordinado as exigências de produtividade postas pelos órgãos de avaliação e financiamento. Aqui, a consequência seria a redução do apoio financeiro e de bolsas de estudo, o que acarretaria a queda de produtividade refletindo-se, também, na qualidade da pós-graduação.

As duas saídas resultam, portanto, igualmente problemáticas, mantendose, assim, embaraçosa a situação. Como resolver o problema? Como sair do dilema? Penso que a argumentação desencadeada ao longo desta exposição já indica, de certo modo, as possíveis saídas.

Em termos radicais, a saída se encontra no rompimento com a lógica do capital. Isso implica a transformação das próprias relações de produção, dando origem a um novo tipo de sociedade. Entretanto, mesmo admitindo que essa seja a meta a ser atingida, sabemos que ela não se faz presente em nosso horizonte imediato. Trata-se, assim, de resistir à lógica dominante reagindo às pressões por meio de ações cujas estratégias devem ser acionadas de acordo com a correlação de forças detectada à luz da análise das situações enfrentadas.

Nessa direção nós podemos, se concluirmos que a correlação de forças é favorável, contestar as razões alegadas para a modificação do mestrado, mostrar as implicações negativas das mudanças propostas e, virando o jogo, deixar claro que são os órgãos oficiais que dependem dos Programas e não o 


\section{movim nto \\ programa de pós-graduação \\ faculdade de educaçã 0 \\ ano 7 - número 14 - Edição Especial - 2020}

contrário, uma vez que é nos Programas de Pós-Graduação que se realizam as atividades-fim e é também daí que provêm os membros das comissões de avaliação e os próprios dirigentes dos órgãos oficiais.

Avaliando-se, porém, que a correlação de forças não é favorável à estratégia acima indicada, deve-se procurar acionar outros tipos de estratégia. Por exemplo: se não é viável alterar os critérios que impõem a redução dos prazos para a conclusão das dissertações de mestrado, pode-se articulá-lo com cursos de especialização, entendidos como um aprofundamento de estudos na área em que o aluno realizará o mestrado. Com isso, mesmo atendendo aos limites temporais definidos pelas agências para o mestrado, dispõe-se de um tempo que, somado à especialização, poderá garantir a qualidade que resultava ameaçada pela redução do tempo do mestrado.

Nesse caso é preciso considerar que o que se implantou no Brasil foi a Pós-Graduação stricto sensu. No Parecer no 977/65 Sucupira reconhece a diferença entre a pós-graduação lato sensu e a stricto sensu, mas não se preocupou com sua regulamentação. Dessa forma, assim como ele considerou que "a regulamentação resulta necessária sob pena do abastardamento inevitável dos graus de Mestre e Doutor", podemos considerar que, não sendo regulamentada, provocou-se o "abastardamento inevitável" da pós lato sensu. Voltada ao aperfeiçoamento, especialização e atualização profissional, a pós lato sensu foi ocorrendo de forma mais ou menos aleatória, à margem da efetiva política de pós-graduação que se restringiu ao stricto sensu.

Diante da não regulamentação, as universidades que decidiram atuar no âmbito da pós-graduação lato sensu o fizeram na forma de cursos de especialização, aperfeiçoamento e extensão criando órgãos específicos para sua organização e gestão do tipo das Coordenação Geral de Especialização, Aperfeiçoamento e Extensão (COGEAEs). Com isso, aquilo que deveria estar articulado como duas modalidades do mesmo setor acadêmico, a pósgraduação, resultou em duas iniciativas inteiramente apartadas uma da outra, materializadas, inclusive, em dois órgãos totalmente separados. 


\section{movim nto \\ programa de pós-graduação \\ faculdade de educação \\ ano 7 - número 14 - Edição Especial - 2020}

Considerando, ainda, que o destaque da regulamentação do nível stricto sensu pelo Conselho Federal de Educação levou as instituições já com certa experiência em pesquisa a se dedicarem apenas ao stricto sensu, o lato senso acabou ficando circunscrito à iniciativa de instituições que se dedicavam dominantemente ao ensino sem, ainda, uma estrutura consolidada de pesquisa. Com isso, os cursos lato sensu foram sendo organizados de forma horizontalizada, segundo o modelo prevalecente na graduação, com várias disciplinas cursadas ao mesmo tempo, quando deveriam, como ocorre no caso do stricto sensu, serem organizados na forma verticalizada com duas ou três disciplinas, no máximo, por semestre, possibilitando, assim, o aprofundamento. Tal discrepância resultou tão evidente que mesmo no caso de instituições, como a PUC de São Paulo, que se dedicaram a ambos os níveis, isso ocorreu de forma inteiramente separada, ficando os Programas de Pós-Graduação stricto sensu localizados num Setor de Pós-Graduação inteiramente apartado dos cursos lato sensu alocados na COGEAE.

Posta essa situação, o papel dos Cursos de Pós-Graduação lato sensu de assegurar, de fato, a especialização, o aperfeiçoamento e a atualização dos profissionais formados nos cursos de graduação resultou prejudicado com o agravante da imagem de um status inferior com que os cursos lato sensu foram estigmatizados diante dos programas stricto sensu.

Diante desse quadro, como indiquei anteriormente, não haveria lugar, no Brasil, para reproduzir a distinção existente nos Estados Unidos entre Mestrados Acadêmicos e Mestrados Profissionais. O que caberia fazer, efetivamente, seria articular o lato sensu com o stricto sensu inserindo os Cursos de Especialização, Aperfeiçoamento e Atualização no próprio Setor de Pós-Graduação, submetendo-os às decisões das Comissões de Pós-Graduação no âmbito das unidades universitárias e à Comissão Central de Pós-Graduação no âmbito da universidade, conferindo-Ihes o mesmo status e assegurando-lhes a mesma qualidade. Foi isso o que tentei fazer quando assumi, entre 1989 e 1992, a coordenação do Programa de Pós-Graduação em Educação da UNICAMP e 


\section{movim nto \\ programa de pós-graduação \\ faculdade de educação \\ ano 7 - número 14 - Edição Especial - 2020}

formulei uma proposta de organização de Cursos de Especialização articulados com o Mestrado. O fato, entretanto, é que, como atesta o "Processo de Bolonha", o modelo americano tende a se impor e nós acabamos não tendo alternativa senão assumir, também aqui no Brasil, a distinção entre mestrado acadêmico e profissional, curvando-nos à exigência de criação dos mestrados profissionais.

\section{Conclusão}

Atentos aos problemas enfrentados, os Programas de Pós-Graduação devem eleger suas prioridades e perseguir firmemente o objetivo que os justifica, isto é, a formação de pesquisadores. A questão da produtividade deverá estar subordinada claramente a esse objetivo e não o inverso, como tem ocorrido atualmente, por efeito da pressão das políticas de investimento e de credenciamento. Ou seja, só vale a pena incrementar a produtividade objetivada em relatórios de pesquisa; nas publicações de artigos e livros; nos trabalhos apresentados nos mais diferentes tipos de eventos que se têm multiplicado na área de educação; e nas dissertações e teses, se os produtos em referência configurarem resultados de pesquisas relevantes sobre os problemas prioritários enfrentados pela educação brasileira.

Por outro lado, constata-se que a pós-graduação caminhou em direção contraposta à graduação, num divórcio que também se manifestou no interior da pós-graduação entre o lato sensu e o stricto sensu, isto é, entre cursos (ensino) e programas (pesquisa). Esse divórcio se acentuou com as reformas dos anos 1990 e com a nova LDB que se encaminharam para a diversificação de modelos de ensino superior, agravando o fenômeno da fragmentação.

Em lugar dessa tendência cabe caminhar no sentido inverso, o da integração, articulando a graduação com a pós-graduação lato e stricto sensu, o que outra coisa não é senão a realização da proclamada indissociabilidade entre ensino e pesquisa. Caberia, então, às unidades universitárias acolher os jovens e colocá-los num ambiente de intenso e exigente estímulo intelectual. Sua formação se iniciaria pelo curso de graduação articulando o ensino dos 


\section{movimento \\ programa de pós-graduação \\ faculdade de educação \\ ano 7 - número 14 - Edição Especial - 2020}

fundamentos teóricos e práticos com a pesquisa propiciada pela inserção dos alunos nos projetos desenvolvidos pelos professores, mediante programas de iniciação científica; prosseguiria com a pós lato sensu, isto é, com cursos de especialização articulados com o mestrado onde, como se mostrou, se daria sua plena iniciação nas lides da pesquisa, completando-se com o doutorado.

Eis como, enfim, poderemos não apenas preservar o novo modelo de formação de pesquisadores construído no Brasil. As análises efetuadas, ainda que circunscritas ao espaço limitado de um simples artigo, procuraram ir além, propondo estratégias conducentes ao aperfeiçoamento e consolidação da exitosa experiência da pós-graduação brasileira.

\section{Referências}

BRASIL. Lei $\mathbf{n}^{\circ}$ 4.024, de 20 de dezembro de 1961. Fixa as Diretrizes e Bases da Educação Nacional. Diário Oficial da União, de 27 de dezembro de 1961.

BRASIL. MINISTÉRIO DA EDUCAÇÃO E CULTURA. CONSELHO FEDERAL DE EDUCAÇÃO. Parecer $\mathbf{n}^{\circ}$ 977/65. Define os cursos de pós-graduação. Documenta,1965, p.67-86.

BRASIL. MINISTÉRIO DA EDUCAÇÃO E CULTURA. CONSELHO FEDERAL DE EDUCAÇÃO. Parecer $\mathbf{n}^{\circ}$ 77/69. Normas do credenciamento dos cursos de pós-graduação. Documenta, $n^{\circ}$ 98, 1969, p. 128-132.

BRASIL. Lei $\mathbf{n}^{\circ}$ 9.394, de 20 de dezembro de 1996. Estabelece as Diretrizes e Bases da Educação Nacional. Diário Oficial da União, de 23 de dezembro de 1996.

CUNHA, Luiz Antônio Constant Rodrigues da. 2. ed. A universidade temporã. Rio de Janeiro, Francisco Alves, 1986.

CURY, Carlos Roberto Jamil. Quadragésimo ano do Parecer CFE n 977/65. Revista Brasileira de Educação, n 30 Set /Out /Nov /Dez, p. 7-20, 2005.

FÁVERO, Maria de Lourdes de Albuquerque. Universidade e poder, 2. ed. Brasília: Plano, 2000.

GHETTI, Maria Cecília. L'Università di Padova tra Repubblica Veneta e Restaurazione (1790-1817). Università di Padova, tesi di Laurea, 1982. 


\section{movim nto \\ programa de pós-graduação \\ faculdade de educação \\ ano 7 - número 14 - Edição Especial - 2020}

MARX, Karl. Contribuição para a crítica da economia política. 2. ed. Lisboa: Estampa, 1973.

SANTONI RUGIU, Antonio. Nostalgia do mestre artesão. Campinas: Autores Associados, 1998.

SAVIANI, Dermeval. Concepção de mestrado centrada na ideia de monografia de base. Educação Brasileira. Revista do Conselho de Reitores das Universidades Brasileira, n. 13, v. 27, p. 159-168, 1991.

SAVIANI, Dermeval. O Lunar de Sepé: paixão, dilemas e perspectivas na educação. Campinas: Autores Associados, 2014.

SAVIANI, Dermeval. Pedagogia Histórico-Crítica, quadragésimo ano: novas aproximações. Campinas: Autores Associados, 2019.

\section{SOBRE O AUTOR}

DERMEVAL SAVIANI é Professor Emérito da Universidade Estadual de Campinas (UNICAMP), Pesquisador Emérito do CNPq e Prof. Titular Permanente do Programa de Pós-Graduação em Educação da UNICAMP.

E-mail: dermevalsaviani@yahoo.com.br

Recebido em: 10.08 .2020

Aceito em: 21.10.2020 